\title{
REAÇÕES DO MERCADO ACIONÁRIO AO ANÚNCIO DE REVISÃO DO RATING DE CRÉDITO SOBERANO DO BRASIL
}

\author{
STOCK MARKET REACTIONS TO THE BRAZIL SOVEREIGN \\ CREDIT RATING REVIEW
}

Claudio Marcelo Edwards Barros

Universidade Federal do Paraná - Brasil

claudiomedwards@hotmail.com

ORCID: : http://orcid.org/0000-0001-7431-1627

Romualdo Douglas Colauto

Universidade Federal do Paraná - Brasil

rdcolauto.ufpr@gmail.com

ORCID: http://orcid.org/0000-0003-3589-9389

\author{
Submissão: 12//2/20|8. Aceitação: 0|/02/2020. \\ Publicação: 31/03/2020. Sistema de avaliação: Double \\ blind review. Universidade FUMEC / FACE, Belo Horizonte \\ - MG, Brasil. Editores Prof. Dr. Mário Teixeira Reis Neto - \\ Prof. Dr. Cid Gonçalves Filho.
}

\section{RESUMO}

Os anos 2008 e 2015 foram particularizados por dois eventos expressivos para o ambiente de negócios brasileiro: elevação para o Grau de Investimento e rebaixamento para Grau Especulativo do rating de crédito soberano. A partir desse contexto, a presente pesquisa teve como objetivo examinar a reação do mercado de capitais brasileiro à elevação ao Grau de Investimento e ao rebaixamento ao Grau Especulativo do rating soberano. Apoiada em pesquisas prévias de abordagem semelhante, foram estabelecidas quatro hipóteses relacionando os anúncios às ações ordinárias e preferenciais de companhias brasileiras. O estudo considerou as empresas listadas no lbovespa no dia da revisão da nota para Grau de Investimento e no dia da revisão para Grau Especulativo. Com aplicação de estudos de eventos, as hipóteses foram examinadas por meio de Análise da Variância e Teste de Sinais para Retornos Anormais e Retornos Anormais Acumulados. Não foram constatados retornos anormais para o evento de elevação do rating de crédito soberano. Condizente com resultados de pesquisas anteriores, a pesquisa mostrou presença de retornos anormais negativos e significativos quando do rebaixamento do rating soberano.

\section{PALAVRAS-CHAVE}

Ratings de crédito soberano. Elevações. Rebaixamentos. Estudo de Eventos. 


\section{ABSTRACT}

The years 2008 and 2015 were characterized by two significant events for the brazilian business environment: upgrade to Investment Grade and downgrade to the Speculative Grade of the sovereign credit rating. In this context, the present research aimed to examine the reaction of the brazilian capital market to the rise to Investment Grade and to the downturn to Speculative Grade of sovereign rating. Supported by previous research with a similar approach, four hypotheses were established relating the announcements to the common and preferred shares of Brazilian companies. The study considered the companies listed on the Ibovespa on the day of revision of the grade for Investment Grade and on the day of revision for Speculative Grade. With the application of event studies, the hypotheses were examined using Analysis of Variance and Signal Testing for Abnormal Returns and Accumulated Abnormal Returns. In line with previous research, there were no abnormal returns for the sovereign credit rating upgrade event and there is significant and negative abnormal return when the sovereign rating was downgraded.

\section{KEYWORDS}

Sovereign credit ratings. Upgrades. Downgrades. Event studies.

\section{INTRODUÇÃO}

As Agências de Rating são entidades privadas e independentes que provêm avaliações sobre a capacidade de pagamento de juros e principal, por parte do emissor, no curto e no longo prazo. Poon e Chan (2008) descrevem que agências de rating têm como propósitos divulgar uma opinião inicial (initial ratings) sobre a solvência de instituições e informar modificações nessas condições por meio de anúncios de rebaixamento (downgrades) e elevação (upgrades) ao longo do tempo. Em termos de agrupamento, os ratings se arranjam em graus de investimento e em graus especulativos e se destinam à avaliação da capacidade de pagamento tanto de corporações privadas e estatais quanto de Governos, sendo para esses últimos aplicados os ratings soberanos.
Sob o enfoque das corporações, o Instituto Brasileiro de Relações com investidores (20I3) menciona que a avaliação de empresas depende da (I) compreensão do risco inerente aos negócios da companhia e sua habilidade em gerenciá-los, (2) do nível de endividamento e (3) da capacidade de geração de caixa. $\mathrm{Na}$ estrutura de endividamento estão custos com capitais de terceiros os quais, à medida que em o rating se deteriora, tendem a aumentar (GRAY, MIRKOVIC e RAGUNATHAN, 2006). E, por consequência, peça chave no exame da probabilidade em honrar compromissos é a capacidade da empresa em produzir caixa (KIM e GU, 2004; LOPEZ, 2007 e MATOUSEK e STEWART, 2009). Tendo em vista a influência destes elementos sobre os ratings das empresas, Langohr e Langohr (2008) notam que as Agências de Rating podem 
exercer papel decisivo na contenção de problemas de assimetria informacional no mercado de ações. O que estaria por trás dessa influência é o impedimento de um investidor em acessar todas as informações de que necessita sobre a realidade subjacente aos negócios da companhia. Embora essa ruptura não alcance preenchimento completo de lacunas informacionais existentes, por exemplo, entre acionistas controladores e minoritários, trata-se de um reforço na habilitação do investidor em compreender melhor o desempenho e valoração das corporações. No nível das corporações, a literatura sobre o conteúdo informacional dos ratings pode ser considerada como bem amadurecida. Pesquisas sugerem que as empresas apresentam pouca reação quando ocorre elevação de seus ratings (GRIFFIN e SANVICENTE, 1982; HOLTHAUSEN e LEFTWICH, I986; BARRON, CLARE e THOMAS, 1997). No outro extremo, são recorrentes as evidências de que os anúncios de rebaixamento de ratings estão associados a retornos anormais negativos e significativos (POON e CHAN, 2008; PURDA, 2007; JORION e ZHANG. 2007; FREITAS e MINARDI, 2013 e MÚRCIA, MÚRCIA e BORBA, 20I3). A literatura relacionada à avaliação do conteúdo informacional ou impacto de alterações de ratings soberanos pode ser também considerada evoluída, o que indica persistente preocupação em se observar a propagação de efeitos para o mercado de capitais quando da revisão de ratings soberanos. Por esse ângulo, vê-se dominância de evidências na direção de indicar que upgrades apresentam pouca ou nenhuma reação e downgrades têm conteúdo informativo de efeito negativo (BROOKS, FAFF, HIILER e HIILER, 2003; BROOKS, FAFF, HIILER e
HIILER, 2004; GANDE e PARSLEY, 2005; FERREIRA e GAMA, 2007; HILL e FAFF, 2010 ;AFONSO, FURCERI e GOMES, 20I2; AFONSO, GOMES e TAAMOUTI, 2014 e CASELLI, GANDOLFI e SOANA, 20I6).

$\mathrm{Na}$ perspectiva do Governo, as agências de classificação de ratings estabelecem a probabilidade de default destes agentes para com agentes econômicos que compõem o mercado de capitais (LANGOHR E LANGOHR, 2008). De acordo com a metodologia adotada pela agência de classificação Standard \& Poors, as decisões de elevação ou rebaixamento de ratings soberanos dependem de diversos fatores, dentre eles 0 risco político e a condução da política fiscal e monetária. Depreende-se disso, que o controle da inflação, a evolução da dívida do país, desempenho da taxa de juros e austeridade fiscal são determinantes para o resultado da avaliação da agência.

Embora os fatores levados em consideração para a construção de ratings soberanos derivem da performance de variáveis macroeconômicas e, portanto, diferentes daquelas utilizadas para determinação de ratings corporativos, defende-se haver ligação entre a valoração de empresas e o resultado de ratings soberanos. Castro (200I) argumenta que embora as ações de empresas não sejam títulos de dívida e, portanto, não sujeitas a default, há uma relação entre o rating soberano e as ações porque se o desempenho da economia pode ser causa para modificações de ratings, então as empresas com negócios nesse país não passariam indiferentes às modificações promovidas em ratings soberanos. Corroborando com essa reflexão, Markoski e Moreira (2010) mencionam que mesmo as ações de empresas não tendo ligação direta a negócios governamentais, controles e po- 
líticas de cunho fiscal, cambial e monetário estão predominantemente sob o domínio do Governo e, portanto, as empresas e as operações do país ficam sujeitas ao rating de crédito do país aonde estão sediadas. A ideia subjacente a esses argumentos está ligada ao fato de que a estabilidade da taxa de juros resulta da propagação de efeitos de políticas fiscal e monetária, as quais dependem predominantemente dos Governos (BARBOZA, 20I5). Sabe-se que a taxa de juros é um balizador para mensuração de ativos livres de risco e, portanto, com influência sobre o dimensionamento do prêmio pelo risco determinado pela diferença entre proxies de retorno de mercado e de ativos livres de risco (SERRA e WICKERT, 2019). Logo, vê-se a influência direta nos métodos de estimação de custo de capital, o que por sua vez poderá afetar de forma rigorosa decisões em investimento de risco. Nessa linha, Maciel e Camargos (2018) mostram que no Brasil o custo de capital é sensível, em termos de redução, aos upgrades do rating soberano. Adicionalmente, é possível observar que nas datas próximas ao downgrade soberano ocorrido em 20I5, a elevação da taxa de juros tornou o prêmio pelo risco negativo, o que se configura como algo supreendentemente ruim para a atratividade de investimentos de risco (BLOOMBERG, 20I6). Seguindo essa linha, Brooks et al. (2004) adicionam que mudanças ocorridas no rating soberano representam um evento crítico capaz de influenciar a revisão de ponderações de carteiras de investimentos internacionais, dado o aumento da percepção de risco propagado pelo país.

Em período de um pouco mais de 7 anos, o Brasil teve sua classificação de rating soberano alterada entre notas que levaram o país ao Grau de Investimento em 30 de abril de 2008 e queda para Grau Especulativo em 09 de setembro de 2015. Esses dois eventos apresentaram forte difusão midiática mundial. A elevação para Grau de Investimento teve repercussão mundial pelo menos por dois motivos peculiares. $O$ primeiro foi que, ainda em 2007, diversos ativos de companhias brasileiras já estavam sendo avaliados com notas de rating no grupo de Grau de Investimento pela Standard \& Poors e o segundo é que seria a primeira vez que o país seria elevado ao Grau de Investimento (BRADIMARTE, 2008). O rebaixamento também teve propagação impactante nos meios de comunicação, sobretudo por se tratar de nota que colocou o rating soberano na categoria de "junk".

Diante deste contexto, propõe-se a seguinte questão de pesquisa: Qual a reação do mercado de ações brasileiro aos anúncios de elevação do rating soberano para Grau de Investimento e seu rebaixamento para Grau Especulativo? A partir da análise de retornos anormais, este estudo tem como objetivo examinar a reação do mercado de capitais brasileiro à elevação ao Grau de Investimento e ao rebaixamento ao Grau Especulativo pela agência de classificação de ratings Standard \& Poors em dois momentos específicos: I) elevação ao Grau de Investimento em 30 de abril de 2008; e 2) rebaixamento para o Grau Especulativo em 09 de setembro de 2015.

Apesar dos reflexos mais aparentes da revisão de créditos soberanos serem sobre os preços de títulos de renda fixa, sua propagação pode atravessar o mercado de acionário. Os ratings têm a capacidade de determinar uma referência para o risco das empresas e do setor financeiro do país, tendendo a onerar as despesas de financia- 
mento de empresas. Por consequência, torna-se um fator para apreçamento do risco de empréstimos bancários e linhas de crédito.Além disso, a publicidade associada ao risco soberano serve como referência para investidores estrangeiros avaliar sua disponibilidade em investir em companhias daquele país (Tesouro Nacional, 2016). Desse modo, a contribuição deste estudo consiste em evidenciar a relevância de reclassificações de risco soberano para as empresas brasileiras listadas na B3 (Brasil, Bolsa, Balcão). Segundo dados do Tesouro Nacional do Brasil, as avaliações soberanas começaram a ser feitas a partir de novembro de 1986. Até o ano de 2008, em nenhuma das avaliações, o grau de investimento fora alcançado, o que veio a ocorrer em abril do mesmo ano. Embora existam outras investigações brasileiras que relacionem rating soberano e mercado acionário, o ineditismo deste estudo está em manifestar empiricamente o impacto no mercado de ações de dois acontecimentos extremos: grau de investimento em 2008 e volta ao grau especulativo em 2015.Assim, salvo melhor juízo, trata-se do primeiro estudo a abordar essa alternância de forma específica.

\section{REVISÃO DA LITERATURA}

Segundo Chan (2008) pesquisas sobre ratings dividem-se em duas áreas temáticas. $\mathrm{Na}$ primeira estão estudos que examinam a influência de variáveis contábeis e de mercado sobre a determinação do rating de empresas. A segunda linha acomoda investigações que abordam a relevância dos ratings para o mercado de capitais, cuja motivação é o exame da influência de classificações ou de reclassificações sobre o valor das ações de empresas listadas em bolsa de valores. Considerando o objetivo pro- posto por esta pesquisa e em linha com os estudos prévios realizados por Erb, Harvey e Viskanta (1996) e Brooks et al. (2003), este trabalho explora a relevância dos ratings soberanos para o mercado de ações brasileiro, no nível individual de empresas listadas em bolsa.

\section{DEFINIÇÕES E ESTRUTURA DAS CLASSIFICAÇÕES DE RISCO}

As maiores Agências de Rating são as empresas Standard \& Poors, Fich e Moody's as quais utilizam escalas de avaliação semelhantes para avaliar instituições financeiras e de serviços financeiros diversificados, tais como bancos, seguradoras e bolsas de valores, como também empresas do setor produtivo e Governos (LANGOHR e LANGOHR, 20I0). Segundo a própria agência internacional de classificação de rating Standard \& Poors (S\&P), rating de crédito se define como uma opinião prospectiva sobre a qualidade do crédito do devedor em relação a uma obrigação financeira especifica, uma classe específica de obrigações ou um programa financeiro. Esta opinião reflete a visão da S\&P sobre a capacidade e a vontade do devedor honrar compromissos financeiros à medida que vencem. No Quadro 0 I detalha-se a estrutura de classificação dos graus de rating por meio de notas.

Observa-se que as notas se dividem em Grau de Investimento e Grau Especulativo, os quais são compostos por 10 e 12 notas, respectivamente. No caso específico da agência S\&P, instrumentos de dívida de empresas e governos recebem notas para itens de curto (moeda local e moeda estrangeira) e longo prazo (moeda local e moeda estrangeira). Ressalte-se que para a condução da presente pesquisa serão utili- 
QUADRO 1 - Categorias de rating da agência de classificação de rating S\&P.

\begin{tabular}{|c|c|c|}
\hline Grau genérico & Nota & Descrição \\
\hline \multirow{4}{*}{$\begin{array}{l}\text { Grau de } \\
\text { Investimento }\end{array}$} & AAA & $\begin{array}{l}\text { Rating mais alto atribuído pela S\&P. Devedor tem capacidade extremamente forte para honrar seus } \\
\text { compromissos financeiros. }\end{array}$ \\
\hline & AA & Capacidade muito forte para honrar compromissos. \\
\hline & A & $\begin{array}{l}\text { Capacidade forte para honrar seus compromissos, mas é mais suscetível a efeitos adversos de } \\
\text { mudanças na economia. }\end{array}$ \\
\hline & BBB & $\begin{array}{l}\text { Capacidade adequada em honrar compromissos financeiros, mas sujeita a condições econômicas } \\
\text { adversas. }\end{array}$ \\
\hline \multirow{5}{*}{$\begin{array}{l}\text { Grau } \\
\text { Especulativo }\end{array}$} & BB & $\begin{array}{l}\text { Primeiro grau de rating especulativo. Devedor é menos vulnerável no curto prazo do que os deve- } \\
\text { dores com ratings mais baixos. No entanto, enfrenta grandes incertezas no momento e exposição } \\
\text { a condições adversas poderiam levá-lo a uma capacidade inadequada para honrar compromissos. }\end{array}$ \\
\hline & B & $\begin{array}{l}\text { Atualmente tem capacidade para honrar seus compromissos financeiros, mas condições adversas } \\
\text { de negócios, financeiras ou econômicas provavelmente prejudicariam a capacidade e a disposição } \\
\text { de pagamento. }\end{array}$ \\
\hline & $\mathrm{CCC}$ & Atualmente vulnerável e dependente de condições favoráveis para honrar seus compromissos. \\
\hline & $\mathrm{CC}$ & Atualmente é altamente vulnerável. \\
\hline & $\mathrm{C}$ & $\begin{array}{l}\text { Um pedido de falência foi apresentado ou ação similar foi tomada. Os pagamentos de compromis- } \\
\text { sos financeiros são continuados. }\end{array}$ \\
\hline
\end{tabular}

Nota: As notas de rating podem apresentar dez subclassificações: (i) Prime: AAA; (ii) Grau elevado: AA-, AA, AA+; (iii) Grau médio elevado: A-, A e A+; (iv) Grau médio baixo: BBB-, BBB e BBB+; (v) Grau de não investimento: BB-, BB e BB+; (vi) Altamente especulativo: $\mathrm{B}-, \mathrm{B}$ e B+; (vii) Risco Substancial: $\mathrm{CCC}+$; (viii) Extremamente especulativo: CCC-; (ix) Em moratória com pequena capacidade de recuperação: C, CC e CCC-; (x) D: em moratória.

Fonte: Adaptado de S\&P (2012).

zadas as graduações de rating de elevação ao grau de investimento e rebaixamento ao grau especulativo da agência Standard \& Poors (S\&P). Os motivos para isso é que esta foi a primeira agência de classificação a fazer as duas revisões de nota em 2008 e 2015 e, portanto, com mais chances de capturar os efeitos de valoração no mercado acionário. Além disso, essa decisão encontra suporte na literatura tendo em conta que Gande e Parsley (2005), Ferreira e Gama (2007), Hill e Faff, dentre outros, observam que a agência S\&P tende a ser mais efetiva em termos de constatação de conteúdo informacional de ratings soberanos.

\section{INVESTIGAÇÕES SOBRE A RELEVÂNCIA DE RATINGS DE CRÉDITO CORPORATIVO}

Nesta etapa são apresentados os principais resultados de pesquisas nacionais e in- ternacionais que examinaram o reflexo de reclassificações de rating sobre o preço de ações, considerando corporações. A classificação dos estudos apresentados a seguir segue a proposta de Múrcia, Múrcia e Borba (20I4), a qual separa os resultados de pesquisas com (i) resultados semelhantes e (ii) diferentes para elevações e rebaixamentos de ratings de empresas.

Os estudos apresentados no Quadro 02 estão ancorados na Hipótese de Mercados Eficientes (FAMA, 1970) em que mudanças de ratings de crédito irão afetar os preços dos ativos analisados se elevações e rebaixamentos contiverem informações novas. Embora os resultados derivem da utilização de abordagens metodológicas semeIhantes (Estudo de Eventos, na maioria), são observáveis desde resultados de irrelevância das mudanças em ratings de crédito até evidências empíricas de presença 
QUADRO 2 - Resultados de pesquisas relacionadas à relevância dos ratings de crédito.

\begin{tabular}{|c|c|c|c|}
\hline Classificação & Ambiente & Principais resultados & Autores \\
\hline \multirow{8}{*}{ 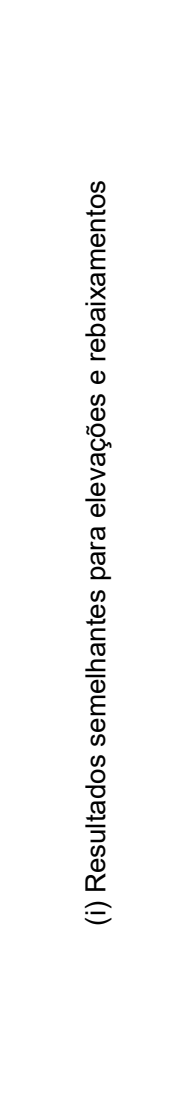 } & $\begin{array}{l}\text { Corporações dos } \\
\text { EUA }\end{array}$ & $\begin{array}{l}\text { Elevações ou rebaixamentos de ratings são integralmente anteci- } \\
\text { pados pelo mercado de ações. Contatada ausência de conteúdo } \\
\text { informacional para modificações nos ratings. }\end{array}$ & $\begin{array}{l}\text { Pinches e Singleton } \\
\text { (1978) }\end{array}$ \\
\hline & $\begin{array}{l}\text { Instituições finan- } \\
\text { ceiras do Brasil }\end{array}$ & $\begin{array}{l}\text { Não há evidências de que o evento de mudança de rating de ins- } \\
\text { tituições financeiras se reflita em retornos anormais significativos. }\end{array}$ & Callado (2008) \\
\hline & $\begin{array}{l}\text { Corporações da } \\
\text { Austrália }\end{array}$ & $\begin{array}{l}\text { Não há evidências de retornos anormais significativos tanto para } \\
\text { elevações quanto para rebaixamentos de ratings. }\end{array}$ & Chan et al. (2009) \\
\hline & $\begin{array}{l}\text { Mercados emer- } \\
\text { gentes }\end{array}$ & $\begin{array}{l}\text { Indícios de que mudanças nos ratings têm relevância em mercados } \\
\text { de ADRs (American Deposit receipts) e não em mercados locais. } \\
\text { Não constataram resultados significativos para elevações ou rebai- } \\
\text { xamentos. }\end{array}$ & Han et al. (2009 \\
\hline & $\begin{array}{l}\text { Índice amplo } \\
\text { Lehman Brothers }\end{array}$ & $\begin{array}{l}\text { Presença de retornos anormais positivos (e significativos) e retor- } \\
\text { nos anormais negativos (e significativos) para elevações e rebaixa- } \\
\text { mentos, respectivamente. }\end{array}$ & $\begin{array}{l}\text { Kliger e Saring } \\
\qquad(2000)\end{array}$ \\
\hline & $\begin{array}{l}\text { Corporações dos } \\
\text { EUA }\end{array}$ & $\begin{array}{l}\text { Retornos anormais cumulativos médios positivos (e significativos) } \\
\text { para elevações e negativos (e significativos) para rebaixamentos. }\end{array}$ & Jorion et al. (2005) \\
\hline & $\begin{array}{l}\text { Corporações da } \\
\text { Austrália }\end{array}$ & $\begin{array}{l}\text { Presença de retornos anormais positivos (e significativos) e retor- } \\
\text { nos anormais negativos (e significativos) para elevações e rebaixa- } \\
\text { mentos, respectivamente. }\end{array}$ & $\begin{array}{l}\text { Creighton et al. } \\
\qquad(2007)\end{array}$ \\
\hline & $\begin{array}{l}\text { Corporações dos } \\
\text { EUA }\end{array}$ & $\begin{array}{l}\text { Observaram a relevância tanto dos rebaixamentos quanto das ele- } \\
\text { vações de rating. No entanto, a reação é mais pronunciada para } \\
\text { elevações de ratings. }\end{array}$ & $\begin{array}{l}\text { Jorion e Zhang } \\
\qquad(2007)\end{array}$ \\
\hline \multirow{6}{*}{ 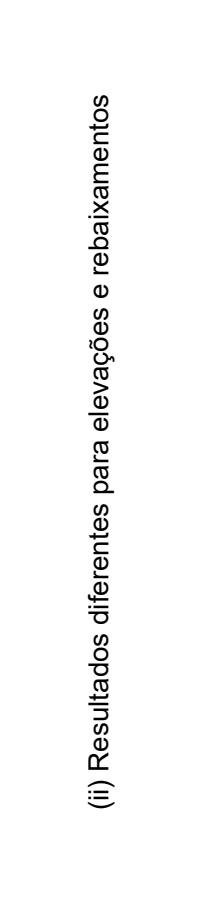 } & $\begin{array}{l}\text { Corporações dos } \\
\text { EUA }\end{array}$ & $\begin{array}{l}\text { Para rebaixamentos de ratings há transmissão de conteúdo } \\
\text { informacional. Para elevações não há constatação de relevância. }\end{array}$ & $\begin{array}{l}\text { Griffin e Sanvicente } \\
\qquad(1982)\end{array}$ \\
\hline & $\begin{array}{l}\text { Corporações dos } \\
\text { EUA }\end{array}$ & $\begin{array}{l}\text { Para rebaixamentos de ratings há transmissão de conteúdo } \\
\text { informacional. Para elevações não há constatação de relevância. }\end{array}$ & $\begin{array}{l}\text { Nayar e Rozeff } \\
\qquad(1994)\end{array}$ \\
\hline & $\begin{array}{l}\text { Corporações dos } \\
\text { EUA }\end{array}$ & $\begin{array}{l}\text { Empresas colocadas em Credit Watch ou que sofreram alterações } \\
\text { de ratings apresentaram retornos anormais não significativos para } \\
\text { elevações e significativos para rebaixamentos. }\end{array}$ & $\begin{array}{l}\text { Hand Holthausen e } \\
\quad \text { Leftwich }\end{array}$ \\
\hline & América Latina & $\begin{array}{l}\text { Examinaram elevações e rebaixamentos, além da inclusão de Cre- } \\
\text { dit Watches e observaram retornos anormais negativos (e significa- } \\
\text { tivos) para rebaixamentos e retornos anormais positivos não signifip } \\
\text { cativos para elevações de ratings. }\end{array}$ & $\begin{array}{l}\text { Freitas e Minardi } \\
\qquad(2013)\end{array}$ \\
\hline & Espanha & $\begin{array}{l}\text { Diferente de estudos prévios, para elevações de ratings foram ob- } \\
\text { servados retornos anormais negativos (e significativos) e ausência } \\
\text { de relevância para rebaixamentos. }\end{array}$ & $\begin{array}{l}\text { Abad-Romero e } \\
\text { Robles e Fernandes } \\
\qquad(2006)\end{array}$ \\
\hline & Brasil & $\begin{array}{l}\text { Por meio de uma amostra de empresas exclusivamente brasileiras, } \\
\text { os autores observaram retornos anormais positivos sem significân- } \\
\text { cia. No entanto, para rebaixamentos foram observados retornos } \\
\text { anormais negativos e significantes. }\end{array}$ & $\begin{array}{l}\text { Múrcia, Múrcia e } \\
\text { Borba (2013) }\end{array}$ \\
\hline
\end{tabular}

Nota: Credit Watch são anúncios realizados por agências de classificação de rating que indicam que o rating de crédito de uma empresa está sob revisão. Geralmente, esse tipo de anúncio é seguido por um rebaixamento do rating de crédito.

Fonte: Adaptado de S\&P. 
de conteúdo informacional dos ratings para ambas as direções (elevação e rebaixamento de ratings de crédito). Estudos adicionais que, simultaneamente, apoiam a irrelevância de elevações de ratings de crédito e a relevância de rebaixamentos estão as investigações de Matolcsy e Lianto (1995), Followill e Martel (1997), Goh e Ederington (1999), Li Shin e Moore (2006). Desse modo, pode-se observar que as evidências mais frequentes tanto em mercados emergentes quanto em mercados desenvolvidos é a presença de conteúdo informacional para rebaixamentos de ratings de crédito.

\section{INVESTIGAÇÕES SOBRE A RELEVÂNCIA DE RATINGS DE CRÉDITO SOBERANO}

Considerando a expressiva e crescente presença de investimentos transnacionais, é notória a influência do desempenho de fundos de investimento sobre o risco-país. Com base nessa percepção, Ederington e Goh (1998) examinaram a presença de conteúdo informacional em 5 medidas de risco-país, sendo 4 delas analisadas a partir do Guia Internacional para Risco-País (ICRG) e uma delas advinda do Risco-País e Rating de crédito para investidores institucionais (CCR). Considerando amostra de 45 países no período 1979-1994, as medidas de risco-país têm associação com medidas que apontam para retornos patrimoniais futuros e com medidas de valoração corporativa. Por meio de inclinações de regressões em dados transversais, $\mathrm{O}$ indicador price-to-book das empresas amostras mostrou-se capaz de explicar $25 \%$ da variabilidade do risco de crédito do país.

Brooks et al. (2004) examinaram a reação do mercado de ações às reclassificações de rating soberano realizadas entre janeiro de I 973 e julho de 200 I pelas agências S\&P, Moody's, Fitch e Thomson. Compõe a amostra de pesquisa todos os países que tiveram revisões em seus ratings soberanos neste período. Por meio da aplicação de Estudo de Eventos e comparações realizadas para o Retorno Anormal Acumulado (CAR), os autores defendem que, tanto para reavaliações de moeda estrangeira quando de moeda local, as reavaliações de elevação não produzem reações. Ao contrário, para rebaixamentos, tanto avaliações de moeda local quanto de moeda estrangeira, produzem efeitos negativamente significativos. Embora o trajeto metodológico dos estudos de Edirigton e Goh (1998) e Brooks et al. (2004) não possam ser comparados, ambos os resultados sugerem relevância dos ratings de crédito soberanos sobre indicadores que influenciam o valor de mercado de empresas listadas. Ao comparar os resultados Brooks et al. (2004) aos resultados de pesquisas cujo percurso metodológico é semelhante, mas os objetivos de pesquisa envolvem o exame do rating de crédito corporativo, observa-se semelhança aos resultados de Griffin e Sanvicente (1982), Nayar e Rozeff (1994), Matolcsy e Lianto (1995) e Li, Shin e Moore (2006).

Cantor e Parker (1996) apresentaram os fatores macroeconômicos que influenciam o rating de crédito dos países. Defenderam que as classificações dadas pela agência de classificação de rating S\&P são explicadas pela (I) variabilidade da renda per capita, (2) pelo crescimento do Produto Interno Bruto, (3) inflação, (4) balanço fiscal, (5) balanço de pagamento, (6) indicador de desenvolvimento econômico e (7) indicador alternativo de precedente default. Tendo em vista que os indicadores que podem descrever os determinantes dados como 
significativos são de conhecimento público e divulgação em periodicidade que pode ser considerada curta (mensais ou trimestrais, por exemplo), não seria, portanto, factível aceitar o fato de haver condução de conteúdo informacional para anúncios de revisões de ratings de crédito soberano. No entanto, ao examinarem por meio de Estudo de Eventos e considerando o valor do dólar como referência para 79 anúncios em 8 países, constataram reação estatisticamente significativa para mudanças de ratings ( $Z$ calculado $2,49 * *$ para uma distribuição binomial com $6 \mathrm{I}, 5 \%$ para contagem chave da pesquisa). Na mesma direção dos estudos de Ederington e Goh (1998) e Brooks et al. (2003) defenderam a relevância dos ratings soberanos.

Com vistas a examinar como revisões de ratings soberanos afetam mercados globais, diversos outros estudos mostram majoritariamente que além do rating soberano ser relevante ele tende a ter um impacto mais pronunciado em revisões de downgrades. Para compreender a presença de efeito propagação (Spillover Effect), Gande e Parsley (2005) evidenciaram que a mudança de classificação de rating de um país tem efeito significativo em outros países. Além disso, mostram que o efeito é assimétrico, tendo em conta que eventos de revisão de ratings positivos no exterior não têm impacto perceptível nos spreads soberanos, enquanto eventos de ratings negativos estão associados a um aumento nos spreads. Em linha temática semelhante ao estudo de Gande e Parsley (2005), Ferreira e Gama (2007) demonstram que mudanças de classificação de um país incorporam informações importantes para os retornos agregados do mercado acionário de outros países. Um rebaixamento de um nível de ra- ting no exterior está associado a um spread negativo e significativo de $5 \mathrm{I}$ pontos base, em média, nos países em que o evento não ocorreu. Nenhum impacto significativo é encontrado para upgrades de classificação.

A partir de 2010 diversas pesquisas estrangeiras mantiveram o propósito de amadurecer investigações sobre a relação entre o mercado de capitais e alterações no rating soberano. Hill e Faff (20I0) examinaram perspectivas de alta e baixa (outlooks) de notas de rating e revisões de rating (ambos soberanos) em I0I países no período de 1990 a 2006. Os achados indicam que em períodos de crise a agência S\&P tende a ser mais efetiva (timeliness effective) que as agências Moody's e Fitch. Fora de períodos de crise, a agência S\&P mantém essa liderança sobretudo em economias não desenvolvidas. Em relação ao conteúdo informacional gerado, afirmam que perspectivas negativas tendem a ser mais informativas que rebaixamentos e, portanto, seriam mais oportunas (timely recognized). Christopher, Kim e Wu (20I2), descrevem que, no longo prazo, repercussões de revisões de notas são positivamente relacionadas ao mercado de ações, o que indica que classificações e perspectivas positivas levam a retornos mais altos no país alvo de revisões de notas e também com efeitos positivos de propagação no mercado acionário de países vizinhos. Por outro lado, para rebaixamentos, investidores internacionais tenderiam a direcionar recursos de países afetados por perspectivas e classificações negativas para o mercado de ações de países não afetados, colocando os ratings soberanos como uma preocupação central em termos de políticas de Governo. E, adicionalmente, reiteram o poder informativo da agência S\&P. Afonso, Furceri e Gomes 
(20I2) utilizaram os CDS (Credit Default Swaps) diários de economias desenvolvidas (União Europeia) para examinar os efeitos de anúncios de elevações e rebaixamento de ratings soberanos por meio de variações anormais. Ressalte-se que, em relação ao tema, condução de estudos de eventos por meio de CDS diários é uma abordagem inédita em pesquisas brasileiras, embora existam dados disponíveis por meio de terminais Bloomberg® e Refinitv $®$. Os autores mostram que enquanto existe uma reação negativa para revisões ou perspectivas de revisões (negativas), a reação ligada a eventos positivos se releva silenciosa, reiterando os achados da linha mais convencional de descobertas prévias.

No entanto, nem sempre ocorrem descobertas na linha de mainstream de pesquisas com temática análoga. É o caso dos estudos de Williams, Alsakka e Gwilym (20I3) e Caselli, Gandolfi e Soana (20I6), os quais examinaram o efeito de alterações de notas e de perspectivas de ratings soberanos sobre as ações de bancos. Os primeiros estudaram mais de 450 bancos de economias emergentes, onde se constou haver conteúdo informacional sobre a valoração de bancos tanto de elevações (efeito positivo nas ações) quanto nos rebaixamentos (efeito negativo) de ratings soberanos. Os resultados de Caselli, Gandolfi e Soana (2016), que consideraram diversos países da Zona do Euro, evidenciam que a repercussão (spillover effect) de alterações de ratings soberanos sobre a valoração dos bancos é fortemente negativa para rebaixamentos e nula para elevações. As quedas no preço das ações se mostraram especialmente mais fortes durante crises econômicas e nos países da sub amostra dos PIIGS (Portugal, Itália, Irlanda, Espanha e Grécia).
No Brasil, Markoski e Moreira (2010) investigaram a sensibilidade do índice lbovespa aos anúncios de rebaixamento e elevações da nota do rating soberano entre 1994 e 2003. Embora não tenham pesquisado a presença de retornos anormais no nível das ações das corporações (ordinárias e preferenciais), defendem a existência de conteúdo informacional das modificações de rating soberano para o mercado de capitais. Afirmaram que, embora os retornos anormais estejam presentes, eles mudam de intensidade a depender do tipo de informação divulgada pelas agências. Correlato a resultados de estudos prévios, os autores concluíram que notícias ruins, ou seja, aquelas que envolvem rebaixamentos, foram mais intensas do que as notícias relacionadas a elevações do rating soberano.

\section{HIPÓTESES DE PESQUISA}

As evidências sobre a relevância de ratings de crédito de empresas indicam não haver uma direção óbvia de reação do mercado de ações para anúncios de elevações ou rebaixamentos. No entanto, tanto do Brasil como do exterior, vê-se uma propensão para resultados mais pronunciados quando se investigam notícias de rebaixamento de notas de rating soberano. Markoski e Moreira $(2010)$ defendem que o teto soberano é restritivo sobretudo em países cuja classificação é especulativa, pois mudanças negativas na nota soberana podem repelir investidores do mercado de ações. $A$ formação de carteiras internacionais requer volume significativo de informações que possam ajustar a posição de investidores de forma que estes maximizem a alocação de recursos (BROOKS et al., 2004). Somado a isso, a presença crescente de carteiras de fundos internacionais tem influenciado 
o aumento da demanda por opiniões de agências de classificação de rating para países já que a percepção do risco do ambiente econômico pode ter influência decisiva sobre o desempenho das corporações naqueles países (CANTOR E PARKER, I 996; LANGOHR E LANGOHR, 2008). Além da importante diversidade metodológica para abordar a ligação entre mercados financeiros e modificações temporais de ratings soberanos de países, o eixo temático que trata esse fenômeno nunca descartou a possibilidade de evidenciação de posições convencionais de reação positiva para upgrades e reações negativas do mercado. No entanto, observa a presença de um cadenciado alicerce empírico tendente a indicar pouco ou nenhum efeito para upgrades e significativo efeito negativo para downgrades soberanos.

Considerando o exposto, estabelecemse as seguintes hipóteses de pesquisa no propósito de compreender a reação do mercado acionário face aos dois eventos aqui apresentados para o caso brasileiro:

$\mathrm{H}^{\text {la: }}$ : $\mathrm{O}$ anúncio de elevação do rating de crédito soberano do Brasil para Grau de Investimento conduziu conteúdo informacional positivo, considerando ações ordinárias;

$\mathrm{H}^{\mathrm{lb}}$ : o anúncio de elevação do rating de crédito soberano do Brasil para Grau de Investimento conduziu conteúdo informacional positivo, considerando ações preferenciais;

$\mathrm{H}^{2 \mathrm{a}}$ : $\mathrm{O}$ anúncio de rebaixamento do rating de crédito soberano do Brasil para Grau especulativo conduziu conteúdo informacional negativo, considerando ações ordinárias;

$\mathrm{H}^{2 \mathrm{~b}}$ : $\mathrm{o}$ anúncio de rebaixamento do rating de crédito soberano do Brasil para Grau especulativo conduziu conteúdo informacional negativo, considerando ações preferenciais;

\section{AMOSTRA E MÉTODOS}

Este é um estudo empírico-analítico que utiliza a metodologia econométrica de Estudo de Eventos para investigar a reação das ações de companhias brasileiras listadas na B3 aos anúncios de reclassificações do rating de crédito soberano efetuadas pela agência de classificação de rating Standard \& Poors. Esse exame é realizado em dois momentos distintos: i) 30 de abril de 2008: elevação da nota BB+ para BBB- em moeda estrangeira para Grau de Investimento; ii) 09 de setembro de 2015: rebaixamento da nota BBB- para BB+ para moeda estrangeira para Grau Especulativo. O objetivo precípuo desta etapa é mostrar os procedimentos técnicos de construção da base de dados usada para a condução da análise dos resultados de forma que se possibilite a replicabilidade no trajeto metodológico utilizado.

\section{Amostra}

No Quadro 3 apresentam-se os ativos que foram utilizados para examinar a reação do mercado de ações aos eventos de reclassificação do rating de crédito.

As empresas que compuseram a amostra são aquelas cujas ações faziam parte do lbovespa em 30 de abril de 2008 e 09 de setembro de 2009. Essa seleção foi realizada pela função members do sistema Bloomberg® utilizada para discriminar ativos que compõem carteiras de mercado em diferentes momentos.

\section{BASE DE DADOS DA PESQUISA}

Sob o ponto de vista operacional, o desenvolvimento do Estudo de Eventos foi realizado em duas etapas. Na primeira foram definidas as janelas de estimação e janela de eventos e na segunda foram cal- 
QUADRO 3 - Ações da amostra para elevação e rebaixamento do rating de crédito soberano.

\begin{tabular}{|c|c|c|c|c|c|c|}
\hline \multicolumn{7}{|c|}{ Ativos: Ações Ordinárias. Data: 30/04/2008. Evento: Elevação para Grau de Investimento } \\
\hline ABEV3 & BBAS3 & BNCA3 & BRFS3 & BRTP3 & BTOW3 & CCPR3 \\
\hline CSAN3 & CSNA3 & CYRE3 & ELET3 & EMBR3 & GFSA3 & LIGT3 \\
\hline LREN3 & NATU3 & PETR3 & SBSP3 & TIMP3 & TNLP3 & VALE3 \\
\hline $\mathrm{CCRO} 3$ & CPFE3 & CRUZ3 & & & & \\
\hline \multicolumn{7}{|c|}{ Ativos: Ações Preferenciais. Data: 30/04/2008. Evento: Elevação para Grau de Investimento } \\
\hline ARCZ6 & BBDC4 & BRAP4 & BRKM5 & BRTP4 & CESP6 & CGAS5 \\
\hline SDIA4 & TAMM4 & TCSL4 & TMAR5 & TMCP4 & TNLP4 & TRPL4 \\
\hline CLSC4 & CMIG4 & CPLE6 & DURA4 & ELET6 & ELPL4 & GGBR4 \\
\hline UBBR4 & UGPA4 & USIM5 & VALE5 & VCPA4 & VIVO4 & VIVT4 \\
\hline GOAU4 & GOLL4 & ITSA4 & ITUB4 & KLBN4 & LAME4 & NETC4 \\
\hline OIBR4 & PCAR4 & PETR4 & ALLL4 & & & \\
\hline \multicolumn{7}{|c|}{ Ativos: Ações Ordinárias. Data: 09/09/2015. Evento: Rebaixamento para Grau Especulativo } \\
\hline ABEV3 & BBSE3 & CRUZ3 & SBSP3 & CSAN3 & RADL3 & BBAS3 \\
\hline CPFE3 & ENBR3 & CIEL3 & QUAL3 & CSNA3 & SMLE3 & NATU3 \\
\hline VALE3 & KROT3 & TIMP3 & ESTC3 & MRFG3 & RENT3 & CYRE3 \\
\hline JBSS3 & FIBR3 & TBLE3 & MULT3 & HGTX3 & HYPE3 & BRML3 \\
\hline PETR3 & BBDC3 & EQTL3 & MRVE3 & CTIP3 & BRPR3 & LREN3 \\
\hline UGPA3 & CCRO3 & EMBR3 & ECOR3 & BVMF3 & ELET3 & BRFS3 \\
\hline \multicolumn{7}{|c|}{ Ativos: Ações Ordinárias. Data: 09/09/2015. Evento: Rebaixamento para Grau Especulativo } \\
\hline ITUB4 & BBDC4 & PETR4 & VALE5 & ITSA4 & VIVT4 & KLBN4 \\
\hline SANB4 & CMIG4 & GGBR4 & BRKM5 & CPLE6 & CESP6 & BRAP4 \\
\hline PCAR4 & SUZB5 & LAME4 & GOLL4 & USIM5 & GOAU4 & OIBR4 \\
\hline
\end{tabular}

Fonte: B3

culados os retornos esperado, anormal e anormal acumulado.

\section{JANELA DE ESTIMAÇÃO}

Segundo Benninga (2009), a janela de estimação é uma série temporal utilizada para calcular o comportamento "normal" dos retornos diários dos preços das ações da empresa e deve conter pelo menos 126 pregões. A janela de estimação é construída tendo como fundamento as variáveis: retorno diário das ações ordinárias e preferenciais das empresas em análise $\left(R_{i}\right)$; e retorno diário do mercado representado pelo lbovespa $\left(R_{m t}\right)$, determinadas conforme a seguir:

$$
\begin{aligned}
& R_{i}=\ln \left(P_{t} / P_{t-1}\right)-I \\
& R_{m t}=\ln \left(C_{t} / C_{t-1}\right)-I
\end{aligned}
$$

Em que,

$P_{t}$ é o preço da ação no momento t;

$P_{t-1}$ é o preço da ação no momento t-I;

$C_{t}$ é a cotação da carteira de mercado no momento t (Ibovespa);

$C_{t-1}$ é a cotação da carteira de mercado no momento t-I (lbovespa);

A aplicação do logaritmo natural mostra que os retornos foram determinados de forma contínua. Aos propósitos definidos neste trabalho, o retorno diário de mercado é representado pela carteira de mercado (lbovespa).

A construção da base de dados para condução de estudos de eventos depende fundamentalmente da estimação dos parâmetros alfa $(\alpha)$ e beta $(\beta)$, os quais são calculados considerando os retornos $R_{i} \mathrm{e}$ $R_{m t}$ na extensão temporal da janela de esti- 
mação definida na pesquisa (Elton, Gruber, Brown e Goetzmann, 20 I2). Esta estimação ocorreu por meio da aplicação de Mínimos Quadrados Ordinários (MQO) na forma de uma regressão linear simples comumente denominada de "modelo de mercado" que tem a seguinte configuração:

$$
R_{i}=\alpha_{i}+\beta R_{m t}+\varepsilon_{i}
$$

O coeficiente $\beta$ representa a inclinação do modelo linear dado pela razão entre a covariância entre os retornos (da empresa e do mercado) e a variância do retorno do mercado. $O$ parâmetro $\alpha$ representa o intercepto que, operacionalmente, é a diferença média entre a variável dependente (retorno diário da empresa) e a variável independente (retorno diário da carteira de mercado), sendo este último associado à estimação da inclinação do modelo linear. Os parâmetros $\alpha$ e $\beta$ servem para a determinação do retorno anormal, definido adiante.

\section{JANELA DE EVENTOS}

Há uma discussão sobre qual o número de dias adequados para a janela de eventos. Em periódicos especializados de contabilidade e finanças é recorrente $o$ uso do intervalo de 5, 3 e 2 dias (CAMARGOS e BARBOSA, 2003; LIMA et al. 2008). Considerando os objetivos propostos por este trabalho, optou-se por uma janela de eventos de 5 dias em torno das datas de elevação e rebaixamento do rating soberano. Deve-se se observar que período utilizado para a construção janela de estimação e o período da janela de eventos são independentes, logo, a janela de estimação não se sobrepõe à janela de eventos sob pena de prejudicar as estimações dos retornos anormais.

\section{DETERMINAÇÃO DOS RETORNOS: ESPERADO,ANORMAL EANORMAL ACUMULADO}

Segundo Mackinlay ( 1997), o retorno esperado $\left(R E_{i}\right)$ é o retorno que o mercado deveria gerar considerando (i) $\circ$ retorno da carteira de mercado daquele dia e (ii) os parâmetros $\alpha$ e $\beta$. Segundo os autores, o retorno anormal $\left(A R_{i}\right)$ é a diferença entre o retorno efetivamente realizado pelas oscilações de preços das ações da empresa $\left(R_{i}\right)$ e o retorno esperado $\left(R E_{i}\right)$, tendo a seguinte configuração:

$$
A R_{i}=R_{i}-\left(\alpha_{i}+\beta_{i} R_{m t}\right)
$$

Portanto, o retorno anormal $\left(A R_{i}\right)$ representa um excedente positivo ou negativo. Caso esse excedente seja substancial, ter-se-á um evento significativo ao nível de $1 \%, 5 \%$ ou $10 \%(* * *, * *$ e $*$, respectivamente). Adicionalmente, serão examinados os retornos anormais acumulados (CAR) para diferentes períodos dentro da janela de eventos, os quais apresentam a configuração a seguir. De acordo com Benninga (p.374, 2008), "O retorno anormal acumulado (CAR) é uma medida de retornos anormais totais durante a janela de eventos. A variável CAR é a soma de todos os retornos anormais do começo da janela de eventos TI até um dia específico t dentro da janela". É determinado por meio da seguinte equação.

$$
\mathrm{CAR}_{\mathrm{i}}=\sum_{\mathrm{t}=0}^{\mathrm{t}} A \mathrm{R}_{\mathrm{TI}+\mathrm{n}}
$$

Ao utilizar o CAR, a ideia de usar a soma dos retornos anormais na janela de eventos ao invés de usar, por exemplo, o produto dos retornos anormais, está ligada ao fato de que os retornos utilizados já estão 
na forma logarítmica, ou seja, não retornos contínuos e podem ser somados. O propósito da utilização de retornos anormais acumulados na presente pesquisa foi 0 de examinar possíveis diferenças apresentadas nas frequências de sinais positivos e negativos nos períodos que compreendem a janela de eventos do estudo, por meio de teste de sinais cuja explicação é detalhada adiante no 3.3.2.

\section{EXAME DO EFEITO AGREGADO DA RECLASSIFICAÇÃO DOS RATINGS SOBERANOS}

A condução do estudo revelou o efeito individualizado sobre cada uma das ações submetidas ao Estudo de Eventos. Dada a necessidade de se fazer inferências sobre - efeito agregado da reclassificação dos ratings soberanos sobre as empresas da amostra, utilizaram-se métodos estatísticos que complementassem os resultados individuais dos retornos anormais diários. Estes métodos foram diferença de médias (ANOVA) e testes de sinais.

\section{EXAME DIFERENÇA DE MÉDIAS}

Para examinar possíveis diferenças de médias dos retornos anormais para os II dias que compõe a janela de eventos foram realizados testes de normalidade cujos resultados são apresentados na Tabela I.

TABELA 1 - Teste de normalidade para os retornos anormais da janela de eventos.

\begin{tabular}{|c|c|c|c|c|}
\hline \multirow{2}{*}{ Janela de Eventos } & \multicolumn{2}{|c|}{ Grau de Investimento } & \multicolumn{2}{|c|}{ Grau Especulativo } \\
\hline & K-S & p-valores & K-S & p-valores \\
\hline 5 Dias antes & 0,923 & 0,362 & 0,895 & 0,399 \\
\hline 4 Dias antes & 0,587 & 0,881 & 1,065 & 0,207 \\
\hline 3 Dias antes & 1,136 & 0,151 & 0,784 & 0,570 \\
\hline 2 Dias antes & 1,274 & 0,078 & 0,780 & 0,576 \\
\hline 1 Dias antes & 0,469 & 0,980 & 0,976 & 0,297 \\
\hline Dia do evento & 0,703 & 0,706 & 0,895 & 0,399 \\
\hline 1 Dias após & 0,701 & 0,709 & 0,775 & 0,586 \\
\hline 2 Dias após & 1,259 & 0,084 & 0,758 & 0,614 \\
\hline 3 Dias após & 0,896 & 0,399 & 0,918 & 0,368 \\
\hline 4 Dias após & 0,788 & 0,563 & 0,395 & 0,998 \\
\hline 5 Dias após & 0,648 & 0,795 & 0,641 & 0,806 \\
\hline
\end{tabular}

Nota: (i) Número de grupos (k): 11 dias. (ii) Teste de Normalidade: Kolmorogov-Smirnov (K-S). (iii) Hipótese nula: a distribuição amostral é normal a 5\%. (iv) Janela de eventos (elevação do rating de crédito): as datas que antecedem o evento são os pregões dos dias 22, 23, 24, 25, 28 e 29 de abril de 2008. As datas que sucedem o evento são os dias 02, 05, 06, 07 e 08 de maio de 2008. (v) Janela de eventos (rebaixamento do rating de crédito) as datas que antecedem o evento são os pregões dos dias $01,02,03$, 04 e 08 de setembro de 2015. As datas que sucedem o evento são os dias 10, 11, 14, 15 e 16 de setembro de 2015. (vi) Retornos anormais: determinados pela diferença $\left.R_{i}-\left[\alpha_{0}+\beta_{i} R_{m}\right]\right)$. ${ }^{* \star},{ }^{* *} \mathrm{e}$ * representam a significância do teste de normalidade ao nível de $1 \%, 5 \%$ e $10 \%$

Fonte: Dados da pesquisa. 
Ao nível de significância de $5 \%$, os retornos anormais apresentam distribuição análoga a distribuição normal, pois não foram rejeitadas as hipóteses de normalidade para todos os dias da janela de eventos considerando tanto o período que cerca a divulgação de elevação do rating de crédito quanto de rebaixamento. Diante desses resultados, possíveis diferenças de médias nos retornos anormais entre os dias que compõe a janela de eventos podem ser examinadas por meio da Análise da Variância (ANOVA). A utilização da diferença de médias entre os dias que compõem a janela de eventos é proposta por Elton et al. (20I2).

\section{TESTE DE SINAIS}

O teste dos sinais se destina a examinar possíveis diferenças nas frequências de sinais positivos e negativos observados em determinada amostra, em lugar de valores numéricos (STEVENSON, I98I). Esse exame teve como objetivo analisar se a frequência de sinais positivos e negativos é capaz de sugerir mais que uma variação aleatória dos retornos anormais.

Para Stevenson (198I), o modelo probabilístico apropriado para situações como essa é a aproximação normal da distribuição binomial com a proporção $p=0,50$. A hipótese nula $\left(H_{0}\right)$ para este teste é de que a reclassificação do rating soberano pela agência de classificação Standard \& Poors não gerou efeito sobre os retornos anormais das ações que compõe a amostra. Embora a aplicação da aproximação normal da distribuição binomial utilize os escores críticos da distribuição normal, a distribuição binomial apresenta momentos (média e variância) específicos, conforme a seguir:

$$
Z=\frac{X_{i}-E(x)}{\sigma(x)}=\frac{X_{i}-n \cdot p}{\sqrt{n \cdot p \cdot q}}
$$

$\mathrm{Na}$ determinação do escore $Z$ da distribuição binomial, $X_{i}$ representa a frequência de sinais positivos (para o evento de elevação do rating) e negativos (para o evento de rebaixamento do rating) observados para a amostra considerando os retornos anormais acumulados para as janelas apresentadas adiante. Pertencente da família de técnicas não paramétricas, a aplicação de estudos de sinais em Estudos de Eventos é de larga utilização em pesquisas empíricas nacionais e internacionais. Em âmbito nacional referências proveitosas são os estudos de Terra e Lima (2006) os quais examinaram a reação do mercado acionário brasileiro para divulgação de resultados ligados a empresas pertencentes a níveis diferenciados de Governança Corporativa, e Lima, Yamamoto, Lima e Malacrida (2008) que investigaram a reação do mercado de ações considerando companhias que divulgam a intenção em emitir ADRs (American Deposit Receipts). No domínio internacional, o teste de sinais já representa um percurso metodológico de utilização consolidada conforme observado por Mackinlay ( I997).

\section{ANÁLISE DOS RESULTADOS}

Essa pesquisa tem o objetivo de examinar a reação do mercado de ações aos anúncios de (I) elevação e (2) rebaixamento do rating de crédito soberano ocorridos em 30 de abril de 2008 e 09 de setembro de 2015 , respectivamente.

\section{ELEVAÇÃO DO RATING DE CRÉDITO SOBERANO}

O objetivo da Tabela 2 é mostrar o resul- 
tado da soma, média e desvio padrão para cada um dos dias da janela de eventos considerando as 63 ações que compunham o lbovespa da data do dia 30 de abril de 2008.

Embora o exame descritivo dos dados não permita comparação entre os retornos anormais, ao considerar a totalidade de dados é possível perceber importante presença de retornos anormais positivos em 4 dias (4I,2 I\% para soma e 0,65\% para média) e 3 dias (20,53\% para soma e 0,33\% para média) antes do evento de divulgação e também no dia do evento (4I,71\% para soma e $0,66 \%$ para média). Considerando os 7 primeiros dias da janela de eventos (5 dias antes e I dia após), há indicação de retornos anormais negativos em maior frequência e magnitude, somente 2 dias antes (-19,8\% para soma e -0,31\% para média) do anúncio de que a nota do rating soberano seria elevada para Grau de Investimento. Ao considerar a janela de eventos completa, os retornos anormais negativos passam a ser maioria a partir do terceiro dia (-4I,00\% para soma e -0,65\% para média) que sucedeu $o$ anúncio. Os resultados su- gerem que os retornos anormais positivos foram, em sua maioria, em datas que precedem o evento, o que insinua reação positiva do mercado para a revisão de elevação do rating de crédito soberano.

Ao se observar individualmente as ações ordinárias, embora os retornos anormais sejam negativos em 5 dias $(-7,48 \%$ na soma e $-0,31 \%$ na média), 2 dias ( $-8,1$ I \% na soma e $-0,34 \%$ na média) e I dia antes do evento $(-4,17 \%$ na soma e $-0,17$ na média), os retornos anormais são positivos no dia do evento $(30,89 \%$ na soma e I,29\% na média). Diferente das ações ordinárias, para as ações preferenciais neste mesmo período, somente em 2 dias antes (- II,6\% na soma e $-0,30 \%$ na média) se observou retornos anormais negativos. Tais resultados indicam um efeito mais pronunciado de retornos anormais positivos nas ações preferenciais.

Tendo em vista que os retornos anormais foram determinados para cada uma das empresas da amostra e para toda a extensão da janela de eventos, e já tendo sido descrito elevados retornos anormais positivos na Tabela 2, na Tabela 3 é possível notar que os

TABELA 2 - Estatísticas descritivas dos retornos anormais da janela de eventos para elevação do rating soberano.

\begin{tabular}{|c|c|c|c|c|c|c|c|c|c|c|c|c|}
\hline Ind. & Fonte & $-5 D$ & $-4 D$ & $-3 D$ & $-2 \mathrm{D}$ & $-1 D$ & $\begin{array}{l}\text { Data do } \\
\text { Evento }\end{array}$ & +1D & $+2 \mathrm{D}$ & $+3 D$ & $+4 D$ & $+5 D$ \\
\hline Soma & \multirow{3}{*}{$\begin{array}{c}\text { Toda } \\
\text { amostra }\end{array}$} & $3,72 \%$ & $41,21 \%$ & $20,53 \%$ & $-19,8 \%$ & $3,53 \%$ & $41,71 \%$ & $12,96 \%$ & $15,03 \%$ & $-41,0 \%$ & $-10,1 \%$ & $-6,86 \%$ \\
\hline Média & & $0,06 \%$ & $0,65 \%$ & $0,33 \%$ & $-0,31 \%$ & $0,06 \%$ & $0,66 \%$ & $0,21 \%$ & $0,24 \%$ & $-0,65 \%$ & $-0,17 \%$ & $-0,11 \%$ \\
\hline D.P & & $1,61 \%$ & $2,14 \%$ & $2,15 \%$ & $2,83 \%$ & $1,97 \%$ & $3,28 \%$ & $4,69 \%$ & $3,07 \%$ & $2,63 \%$ & $2,15 \%$ & $1,89 \%$ \\
\hline Soma & \multirow{3}{*}{ ON } & $-7,48 \%$ & $13,87 \%$ & $19,66 \%$ & $-8,11 \%$ & $-4,17 \%$ & $30,89 \%$ & $15,18 \%$ & $1,09 \%$ & $-21,8 \%$ & $-4,29 \%$ & $-6,19 \%$ \\
\hline Média & & $-0,31 \%$ & $0,58 \%$ & $0,82 \%$ & $-0,34 \%$ & $-0,17 \%$ & $1,29 \%$ & $0,63 \%$ & $0,05 \%$ & $-0,91 \%$ & $-0,18 \%$ & $-0,26 \%$ \\
\hline D. P. & & $1,67 \%$ & $2,05 \%$ & $2,05 \%$ & $3,24 \%$ & $1,84 \%$ & $4,31 \%$ & $5,68 \%$ & $2,49 \%$ & $3,10 \%$ & $2,58 \%$ & $2,34 \%$ \\
\hline Soma & \multirow{3}{*}{ PN } & $11,21 \%$ & $27,34 \%$ & $0,87 \%$ & $-11,6 \%$ & $7,70 \%$ & $10,83 \%$ & $-2,22 \%$ & $13,94 \%$ & $-19,2 \%$ & $-6,12 \%$ & $-0,67 \%$ \\
\hline Média & & $0,29 \%$ & $0,70 \%$ & $0,02 \%$ & $-0,30 \%$ & $0,20 \%$ & $0,28 \%$ & $-0,06 \%$ & $0,36 \%$ & $-0,49 \%$ & $-0,16 \%$ & $-0,02 \%$ \\
\hline D. P. & & $1,551 \%$ & $2,209 \%$ & $2,180 \%$ & $2,589 \%$ & $2,050 \%$ & $2,423 \%$ & $4,026 \%$ & $3,404 \%$ & $2,319 \%$ & $1,879 \%$ & $1,582 \%$ \\
\hline
\end{tabular}

Nota: (i) Janela de eventos: as datas que antecedem o evento (30 de abril de 2008) são os pregões dos dias 22, 23, 24, 25, 28 e 29 de abril de 2008. As datas que sucedem o evento são os dias 02, 05, 06, 07 e 08 de maio de 2008. (ii) Janela de estimação: determinada para 126 pregões que antecedem a janela de eventos; (iii) Retornos anormais: determinado pela diferença $R_{i}-\left[\alpha_{0}+\beta_{i} R_{m}\right]$ ); (v) D.P.: representa o desvio padrão dos retornos anormais para cada dia da janela de eventos.

Fonte: Dados da pesquisa. 
saltos médios dos retornos anormais representam diferenças médias em cada um dos dias. Assim, nesta etapa, empregou-se Análise da Variância (ANOVA).

Os resultados mostram que tanto para amostra completa como para as amostras separadas por classes de ativos, há muito mais variância dentro dos dias do que entre os dias, o que resulta em baixo valor para a razão que determina o $F$ calculado. Desse modo, em nível de significância de $5 \%$ e considerando que os valores críticos de $F$ se mostraram superiores aos valores calculados, não é possível rejeitar a hipótese nula de igualdade entre as médias dos retornos anormais dos II dias da janela de eventos. A partir desses resultados, não foi possível afirmar que os retornos anormais nas datas ao redor do evento de divulgação da elevação do rating de crédito soberano para Grau de Investimento contenham elevações substanciais dos retornos anormais das empresas listadas no Ibovespa. Com isso, não é possível confirmar as hipóteses Hla e HIb de existência de conteúdo informacional trazido pela notícia de elevação do rating para Grau de Investimento. Consequentemente, os resultados evidenciam ausência de conteúdo informacional conduzido ao mercado de ações para a circunstância de elevações do rating de crédito soberano. Tais resultados se põem em harmonia aos achados das investigações de Brooks et al. (2004), Gande e Parsley (2005), Afonso, Furceri e Gomes (2012), Afonso, Gomes e Tammouti (20l4), Ferreira e Gama (2007) e Caselli, Gandolfi e Soana (20/6) e em relação à estudos nacionais guardam relação direta aos achados de Moreira e Markoski (20I0).

\section{REBAIXAMENTO DO RATING DE CRÉDITO SOBERANO}

Apresenta-se a Tabela 4 a estatística descritiva para cada um dos dias da janela de eventos considerando as 63 ações que compunham o lbovespa em 09 de setembro de 2015, dada em que a agência de classificação de rating Standard \& Poors rebaixou o rating de crédito soberano de BBB- para BB+ para moeda estrangeira.

Os dados apontam forte presença de retornos anormais negativos para 5 dias antes (-22,7\% na soma e - 0,36 na média), 4 dias depois ( $-20 \%$ na soma e $-0,3 \%$ na média) e para o dia do evento (- | $4,53 \%$ e -0,23\%). No entanto, a intensidade de retornos anormais negativos fica mais pronunciada quando

TABELA 3 - Diferenças entre retornos anormais da janela de eventos para elevação do rating soberano.

\begin{tabular}{l|c|c|c|c|c|c}
\hline & \multicolumn{2}{|c|}{$\begin{array}{c}\text { Toda a amostra } \\
\mathbf{n = 6 3}\end{array}$} & \multicolumn{2}{c|}{$\begin{array}{c}\text { Ações Ordinárias } \\
\mathbf{n = 2 4}\end{array}$} & \multicolumn{2}{c}{$\begin{array}{c}\text { Ações Preferenciais } \\
\mathbf{n = 3 9}\end{array}$} \\
\hline Fonte da variação & $S Q$ & $M Q$ & $S Q$ & $M Q$ & $S Q$ & $M Q$ \\
\hline Entre os dias & 0,010 & 0,001 & 0,010 & 0,001 & 0,00435 & 0,00044 \\
\hline Dentro dos dias & 0,502 & 0,001 & 0,239 & 0,001 & 0,25844 & 0,00062 \\
\hline F Calculado & \multicolumn{2}{|c|}{1,3320} & \multicolumn{2}{|c|}{1,0424} & \multicolumn{2}{c}{0,7043}
\end{tabular}

Nota: (i) SQ: representam as Somas dos Quadrados entre os dias e Somas dos quadrados dentro dos dias observados na janela de eventos; (ii) MQ: representam a média dos quadrados entre os dias (associada a $k-1$ graus de liberdade) e a média dos quadrados dentro dos dias (associada a $n-k$ graus de liberdade); (iii) $n$ : representam o número de ações submetidas ao Estudo de Eventos. (iv) $F$ tabelado: 1,845 para $n=63,1,686$ para $n=24$ e 1,853 para $n=39$; (v) $F$ calculado: razão entre a média dos quadrados entre os dias e média dos quadros dentro dos dias com $k-1$ e $k$ - $n$ graus de liberdade, respectivamente. ${ }^{* * *}$, ${ }^{* *} \mathbf{e}^{*}$ representam a significância ao nível de $1 \%, 5 \%$ e $10 \%$.

Fonte: Dados da pesquisa. 
TABELA 4 - Estatísticas descritivas dos retornos anormais da janela de eventos para rebaixamento do rating de crédito soberano.

\begin{tabular}{|c|c|c|c|c|c|c|c|c|c|c|c|c|}
\hline Ind. & Fonte & $-5 D$ & $-4 D$ & $-3 D$ & $-2 D$ & $-1 \mathrm{D}$ & $\begin{array}{l}\text { Data do } \\
\text { Evento }\end{array}$ & +1D & $+2 \mathrm{D}$ & $+3 D$ & $+4 D$ & $+5 \mathrm{D}$ \\
\hline Soma & \multirow{3}{*}{$\begin{array}{c}\text { Toda } \\
\text { Amostra }\end{array}$} & $-22,7 \%$ & $14,74 \%$ & $8,14 \%$ & $24,51 \%$ & $12,58 \%$ & $-14,53 \%$ & $51,18 \%$ & $30,98 \%$ & $1,34 \%$ & $-20 \%$ & $43,61 \%$ \\
\hline Média & & $-0,36 \%$ & $0,23 \%$ & $0,13 \%$ & $0,39 \%$ & $0,20 \%$ & $-0,23 \%$ & $0,81 \%$ & $0,49 \%$ & $0,02 \%$ & $-0,3 \%$ & $0,69 \%$ \\
\hline D.P. & & $2,72 \%$ & $3,20 \%$ & $2,13 \%$ & $2,89 \%$ & $2,63 \%$ & $2,30 \%$ & $3,54 \%$ & $3,04 \%$ & $3,19 \%$ & $2,17 \%$ & $2,21 \%$ \\
\hline Soma & \multirow{3}{*}{ ON } & $-38,8 \%$ & $-26,4 \%$ & $17,86 \%$ & $-1,55 \%$ & $2,81 \%$ & $-15,78 \%$ & $13,13 \%$ & $15,32 \%$ & $21,97 \%$ & $-27, \%$ & $35,67 \%$ \\
\hline Média & & $-0,92 \%$ & $-0,63 \%$ & $0,43 \%$ & $-0,04 \%$ & $0,07 \%$ & $-0,38 \%$ & $0,31 \%$ & $0,36 \%$ & $0,52 \%$ & $-0,6 \%$ & $0,85 \%$ \\
\hline D.P. & & $2,07 \%$ & $2,55 \%$ & $2,10 \%$ & $2,43 \%$ & $2,14 \%$ & $2,58 \%$ & $2,97 \%$ & $2,76 \%$ & $2,23 \%$ & $2,16 \%$ & $2,07 \%$ \\
\hline Soma & \multirow{3}{*}{ PN } & $16,09 \%$ & $41,20 \%$ & $-9,72 \%$ & $26,06 \%$ & $9,77 \%$ & $1,25 \%$ & $38,05 \%$ & $15,66 \%$ & $-20,6 \%$ & $6,49 \%$ & $7,94 \%$ \\
\hline Média & & $0,77 \%$ & $1,96 \%$ & $-0,46 \%$ & $1,24 \%$ & $0,47 \%$ & $0,06 \%$ & $1,81 \%$ & $0,75 \%$ & $-0,98 \%$ & $0,31 \%$ & $0,38 \%$ \\
\hline D.P. & & $3,49 \%$ & $3,70 \%$ & $2,13 \%$ & $3,56 \%$ & $3,44 \%$ & $1,61 \%$ & $4,38 \%$ & $3,58 \%$ & $4,45 \%$ & $2,09 \%$ & $2,50 \%$ \\
\hline
\end{tabular}

Nota: (i) Janela de eventos: as datas que antecedem o evento (09 de setembro 2015) são os pregões dos dias $01,02,03,04$ e 08 de setembro de 2015. As datas que sucedem o evento são os dias 10,11,14, 15 e 16 de setembro de 2015. (ii) Janela de estimação: determinada para 126 pregões que antecedem a janela de eventos; (iii) Retornos anormais: determinado pela diferença $\left.R_{i}-\left[\alpha_{0}+\beta_{i} R_{m}\right]\right) ;(v)$ D.P.: representa o desvio padrão dos retornos anormais para cada dia da janela de eventos.

Fonte: Dados da pesquisa.

se observa as ações ordinárias. Para essas ações há intensos retornos anormais negativos em $5(-38,8 \%$ na soma e $-0,92 \%$ na média), 4 (-26,4\% na soma e $-0,63 \%$ na média), 2 (-I,55\% na soma e $-0,04 \%$ na média) dias antes, 4 dias após (-27\% na soma e - $-0,6 \%$ na média) e no dia do evento $(-15,78 \%$ na soma e $-0,38 \%$ na média). Para ações preferenciais, há mais intensidade de retornos anormais positivos.

Considerando as datas nas cercanias do anúncio de revisão do rating soberano que rebaixou a nota para Grau Especulativo, na Tabela 5 evidenciam-se diferenças nos retornos anormais considerando cada um dos dias da janela de eventos.

Observa-se que para a amostra completa não há diferenças substanciais nos retornos anormais para os II dias que compreendem a janela de eventos. No entanto, este panorama se altera quando se subdivide a amostra. Para as ações ordinárias, em nível de significância de $1 \%$ e considerando os níveis críticos para o teste $F$, há evidências de que nem todas as médias são iguais entre os dias posicionados ao redor da data do anúncio de rebaixamento do rating soberano. $O$ $\mathrm{p}$-valor associado ao teste $\mathrm{F}$ calculado, cujo

TABELA 5 - Diferenças entre retornos anormais da janela de eventos para rebaixamento do rating de crédito soberano.

\begin{tabular}{c|c|c|c|c|c|c}
\hline & \multicolumn{2}{|c|}{ Toda a amostra } & \multicolumn{2}{c|}{ Ações ordinárias } & \multicolumn{2}{c}{ Ações Preferenciais } \\
\cline { 2 - 8 } & \multicolumn{2}{|c|}{$\mathbf{n = 6 3}$} & \multicolumn{2}{c}{$\mathbf{n = 4 2}$} & \multicolumn{2}{c}{$\mathbf{n = 2 1}$} \\
\hline Fonte da variação & $\mathrm{SQ}$ & $\mathrm{MQ}$ & $\mathrm{SQ}$ & $\mathrm{MQ}$ & $\mathrm{SQ}$ & $\mathrm{MQ}$ \\
\hline Entre os dias & 0,010 & 0,001 & 0,014 & 0,001 & 0,016 & 0,002 \\
\hline Dentro dos dias & 0,522 & 0,001 & 0,257 & 0,001 & 0,240 & \multicolumn{2}{c}{1,513} \\
\hline F Calculado & \multicolumn{2}{|c|}{1,281} & \multicolumn{2}{c|}{$2,380^{* \star *}$}
\end{tabular}

Nota: (i) SQ: representam as Somas dos Quadrados entre os dias e Somas dos quadrados dentro dos dias observados na janela de eventos; (ii) MQ: representam a média dos quadrados entre os dias (associada a $k-1$ graus de liberdade) e a média dos quadrados dentro dos dias (associada a $n-k$ graus de liberdade). (iii) $n$ : representam o número de ações submetidas ao Estudo de Eventos. (iv) $F$ tabelado: 1,845 para $n=63,1,852$ para $n=24$ e 1,874 para $n=39$; (v) $F$ calculado: razão entre a média dos quadrados entre os dias e média dos quadros dentro dos dias com $k-1$ e $k-n$ graus de liberdade, respectivamente. ${ }^{* * *},{ }^{* *} \mathrm{e}^{*}$ representam a significância ao nível de $1 \%, 5 \%$ e $10 \%$.

Fonte: Dados da pesquisa. 
resultado foi de 2,380 , é de 0,0093 , sendo rejeitada a hipótese nula de igualdade de médias. Considerando a evidenciação dessa diferença, as tabelas apresentadas a seguir forneceram indícios para exame da hipótese que envolve ações ordinárias.

Tendo em vista a detecção de uma diferença significativa nos retornos anormais das ações ordinárias, a Tabela 6 complementa a Tabela 4 ao demonstrar os resultados do Estudo de Eventos para este recorte amostral. Pode-se observar as frequências de sinais negativos e positivos para retornos anormais acumulados (CAR) para três janelas distintas.

Nota-se que para as ações ordinárias, há elevada frequência de retornos negativos nas três janelas. A Janela I, que considera os retornos anormais acumulados nos dias 0I, 02, 03, 04 e 08 de Setembro de 2015 (soma de $-5 D$ até $-I D$, soma de $-4 D$ até -ID e assim sucessivamente), mostra que os retornos anormais acumulados negativos diferem dos positivos significativamente em nível de 10\%. Embora os retornos anormais acumulados se mantenham na maioria negativos, quando se considera 4 dias antes até I dia antes do evento, eles deixam de ser significativos. Para os demais dias da Janela I, os retornos anormais acumulados positivos passam a ser maioria, embora não sejam significativos sob o ponto de vista estatístico.

$\mathrm{Na}$ Janela 02, que considera os dias 01 , 02, 03, 04, 08 e 09 de setembro de 2015 (soma de -5D até o evento, soma de -4D até $\circ$ evento e assim sucessivamente), a frequência de retornos anormais acumulados negativos supera os negativos significativamente ao nível de 10\%.A Janela 2 indica ainda que no dia do evento os retornos anormais acumulados negativos e positivos apresentam a mesma frequência.

Por fim, na Janela 3 , que considera os dias 0I, 02, 03, 04, 08, 09 e I 0 de Setembro de 2015 (soma de -5D até +ID, soma de $-4 D$ até $+I D$ e assim sucessivamente), os retornos anormais acumulados negativos diferem dos positivos significativamente ao nível de $5 \%$ quando se considera todo o intervalo de retornos anormais e ao nível

TABELA 6 - Retornos Anormais Acumulados para ações ON para rebaixamento do rating de crédito soberano.

\begin{tabular}{|c|c|c|c|c|c|c|c|c|c|}
\hline \multirow[t]{2}{*}{ Janelas } & \multicolumn{3}{|c|}{$\begin{array}{c}\text { Janela } 01 \\
n=42\end{array}$} & \multicolumn{3}{|c|}{$\begin{array}{c}\text { Janela } 02 \\
n=42\end{array}$} & \multicolumn{3}{|c|}{$\begin{array}{c}\text { Janela } 03 \\
n=42\end{array}$} \\
\hline & CAR “+” & CAR “-” & Z & CAR “+” & CAR “-” & Z & CAR “+” & CAR “-” & Z \\
\hline 5 Dias antes & 16 & 26 & $-1,5430^{*}$ & 16 & 26 & $-1,5430^{*}$ & 15 & 27 & $-1,852^{\star *}$ \\
\hline 4 Dias antes & 18 & 24 & $-0,9258$ & 16 & 26 & $-1,5430^{*}$ & 16 & 26 & $-1,543^{*}$ \\
\hline 3 Dias antes & 24 & 18 & 0,9258 & 24 & 18 & 0,9258 & 23 & 19 & 0,617 \\
\hline 2 Dias antes & 24 & 18 & 0,9258 & 18 & 24 & $-0,9258$ & 18 & 24 & $-0,926$ \\
\hline 1 Dia antes & 25 & 17 & 1,2344 & 19 & 23 & $-0,6172$ & 20 & 22 & $-0,309$ \\
\hline Evento & & & & 21 & 21 & 0,0000 & 21 & 21 & 0,000 \\
\hline 1 Dia após & & & & & & & 22 & 20 & 0,309 \\
\hline
\end{tabular}

Nota: (i) Janela 1: Considera 5 dias antes (-5D) do evento até 1 dia antes do evento (-1D); (ii) Janela 2: Considera 5 dias antes (-5D) do evento até o dia do evento; (iii) Janela 3: Considera 5 dias antes (-5D) do evento até um dia após (+1) o anúncio de mudança no rating de crédito soberano; (iv) Média e Desvio padrão: como são 42 observações a média é $21\left(0,5^{\star} 42\right)$ e o desvio padrão é 3,24 dado por

(v) Teste hipótese: unicaudal à esquerda. Hipótese nula: $50 \%$ dos sinais são retornos anormais são acumulados negativos. (vi) Valores críticos de Z: são 1,28, 1,64 e 2,33, para 1\%, 5\% e 10\% de significância, respectivamente. * ${ }^{* *} e^{* * *}$ significativos ao nível de $1 \%, 5 \%$ e $10 \%$, respectivamente.

Fonte: Dados da pesquisa. 
de $10 \%$ quando se considera 4 dias antes até um dia após o evento.

Os resultados apresentados a partir das Tabelas 5 e 6 fornecem evidências que apoiam, em nível de $5 \%$ e $10 \%$, a confirmação da hipótese $\mathrm{H} 2 \mathrm{a}$ e refutação da hipótese $\mathrm{H} 2 \mathrm{~b}$. $\mathrm{O}$ exame dos dados sustentou que para as ações ordinárias o anúncio de revisão para rebaixamento do rating de crédito soberano conduz conteúdo informacional ao mercado de ações. No entanto, para ações preferenciais, não há índicos para sustentar a presença de relevância do anúncio de revisão para rebaixamento do rating de crédito. Apesar de não haver separação em classes de ativos nos estudos realizados por Brooks et al. (2004) e pesquisas seguintes a eles, estes resultados são semelhantes ao daquelas pesquisas ao indicar a relevância das notas de rating de crédito soberano para reclassificações envolvendo rebaixamentos. Esses achados também corroboram aos resultados defendidos por Markoski e Moreira (2010) que da mesma forma apontam o efeito mais pronunciado dos anúncios de rebaixamento do que de elevação de ratings soberanos no Brasil.

A mensagem econômica presente nos resultados das análises das hipóteses nos tópicos "Elevação do rating de crédito soberano" e "Rebaixamento do rating de crédito soberano" reforça a compreensão de que classificações de rating soberano necessitam compor o conjunto de políticas prudenciais do país porque a dimensão soberana de classificação pode impor ao ambiente das empresas efeitos adversos, o que é coerente à linha de argumentação dos estudos desenvolvidos por Christopher, Kim e Wu (2012). Tendo em conta que a determinação de retornos anormais é feita a partir dos preços de mercado das ações, o que nada mais é do que o valor do patrimônio líquido das companhias listadas em bolsa a valor de mercado (Equity Market), as revisões do rating soberano para grau especulativo indicaram destruição de valor de mercado de companhias brasileiras, o que revela uma das faces nocivas do efeito propagador de incertezas ligadas a política econômica escolhida e conduzida pelo Governo central. Nessa lógica, tais resultados são congruentes aos achados de Brooks et al. (2004), Ferreira e Gama (2007), Hill e Faff (2010) e Caselli, Gandolfi e Soana (2016) quando defendem a capacidade de destruição de riqueza quando dos anúncios de rebaixamento de rating soberano. O escrutínio de investidores e de fundos de investimento em relação às decisões em empreendimentos dependem sobremaneira de medidas rigorosas para balizar decisões de alocação de recursos em dimensão internacional, dentre elas o rating soberano. Nesse sentido, o amparo soberano tem a capacidade de apontar em que ambiente macro e microeconômico estes investimentos irão se maturar. No Brasil, como defendem Maciel e Camargos (2018), o custo de capital é sensível à upgrades, o que reforça a condição de que um ambiente econômico amigável e também atrativo à alocação de investimentos transnacionais (e também nacionais) passa pela cobertura do rating soberano. Por sua vez, os indícios dessa pesquisa sugerem que ratings decrescentes em qualidade tendem a criar um cenário propenso a repelir investimentos de risco tendo em conta a valoração negativa a que se expõem as empresas.

\section{CONCLUSÕES}

Visando contribuir para a evidenciação da relevância de reclassificações de ratings 
de crédito soberano do Brasil, este trabalho examinou a reação do mercado de ações brasileiro para a elevação do rating soberano para Grau de Investimento e rebaixamento para Grau Especulativo pela agência de classificação de rating Standard and Poors. Apoiando-se em resultados de pesquisas prévias sobre a reação do mercado de ações para modificações no rating corporativo e em pesquisas de reclassificações do rating soberano (BROOKS, et al. 2003 e MARKOSKI e MOREIRA, 20I0), esta pesquisa apresentou os seguintes resultados: i) para elevação do rating de crédito soberano em 30 de abril de 2008: a reclassificação para moeda estrangeira que elevou o rating para Grau de Investimento não produziu reações detectáveis por meio de retornos anormais positivos e significativos.

Com isso, não foi constatado condução de conteúdo informacional quando da reclassificação do rating de crédito soberano de $\mathrm{BB}+$ para BBB-, tanto para ações preferenciais quanto para ações ordinárias; ii) para rebaixamento do rating de crédito soberano em 09 de setembro de 2015: a reclassificação para moeda estrangeira que rebaixou o rating para Grau Especulativo produziu reações detectáveis exclusivamente para ações ordinárias. Desse modo, os resultados do estudo sugerem a geração de conteúdo novo quando do rebaixamento, o que parcialmente é condizente o com o resultado de pesquisas internacionais precedentes. A partir desses resultados é possível fazer pelo menos duas observações.

A ausência de conteúdo informacional para o evento envolvendo a elevação do rating de crédito pode ser explicada pelo fato de que as boas notícias podem ter sido levadas ao preço das ações ao longo do tempo que antecedeu ao anúncio de ele- vação. Pode-se aduzir que a elevação para Grau de Investimento era uma graduação de rating já esperada porque os indicadores que são influentes para sua determinação já se mostravam consolidados ou em consolidação avançada. Um dos indícios de que a elevação já era esperada é o fato de que mesmo antes de abril de 2008 , ativos de empresas brasileiras já estavam sendo avaliados pela Standard \& Poors acima do rating soberano do Brasil.Assim, a elevação para Grau de Investimento não criou porção significativa de valoração em datas próximas da divulgação do evento.

Embora seja possível argumentar que investidores já conhecessem a deterioração dos determinantes do rating soberano do Brasil antes da agência S\&P fazer o anúncio de rebaixamento em setembro de 2015, investidores com ações ordinárias podem ter revisado suas posições mostrando mais sensibilidade às notícias ruins. Em parte, essas modificações de posição podem ser explicadas pelo fato de muitos fundos de investimentos dependerem de avaliações favoráveis de agências de classificação de risco, as quais podem inclusive influenciar a continuidade de investimentos em companhias brasileiras. $O$ rebaixamento do rating soberano apresentaria efeito mais pronunciado do que sua elevação, porque o que estava em questão era perda do Grau de Investimento, o que prejudica as referências em termos de risco e custo de dívida do país, que por sua vez têm efeito decisivo sobre a continuidade de investimentos, além de interferir na expectativa de resultados de investimentos já realizados.

O caminho percorrido para o desenvolvimento desse estudo, tanto em função da linha temática de exploração quanto em razão das diversas abordagens metodoló- 
gicas encontradas, permite indicar estudos futuros por meio inclusive de fontes de dados disponíveis. Parafraseando Múrcia, Múrcia e Borba (p.90, 2014) "O cenário nacional tende a fornecer um interessante laboratório para pesquisas empíricas (...). A primeira delas é que a questão de pesquisa tratada nesse estudo pode ser aplicada às empresas que pertencem ao segmento de Small Caps, ou seja, consideradas de pequena capitalização. Por meio do composite brasileiro SmallII é possível identificar essas empresas e ter um ponto de partida para a definição de uma amostra para análise. A segunda é que as bases de dados refinitv ${ }^{\circledR}$ (antigo Thomson Reuters) e Bloomberg® disponibilizam longas séries de dados para CDS (Credit Defaut Swaps), as quais são proxies largamente utilizadas para risco-país. Como são séries diárias, uma sugestão de pesquisa seria examinar se os CDS, via variações anormais, têm a capacidade de antecipar mudanças de notas soberanas dadas pelas Agências de Classificação de risco. Além disso, essas bases de dados geram proxies agregadas (e, portanto, no nível país) do prêmio pelo risco em frequência diária (Bloomberg via função CRP) onde seria possível investigar a evolução da influência do risco-país sobre o prêmio pelo risco, sendo possível assim relacionar evolução de rating soberano, risco-país e custo de capital. E, finalmente, uma possibilidade de estudo futuro é examinar a evolução (no nível agregado e no nível da firma) das decisões de investimento (via Capex - Capital Expenditures, por exemplo) face a deterioração e/ou recomposição do rating soberano.

Ressalte-se que embora a data de abril de 2008 (upgrade soberano para grau de investimento) e de setembro de 2015 (downgrade para grau especulativo) sejam bastante expressivas para o estudo dessa temática no Brasil, tem-se como limitação dessa pesquisa a não inclusão de toda a série de revisões intermediárias (das escalas de ratings soberanos) e perspectivas (outlooks) de alta ou baixa da graduação do rating do Brasil dadas pela agência Standard and Poors.Além disso, esse estudo considerou uma janela de eventos específica de II dias úteis, o que não pode ser considerado um interregno definitivo de propagação de retornos anormais. 


\section{REFERÊNCIAS}

AFONSO, António; FURCERI, Davide; GOMES, Pedro. Sovereign credit ratings and financial markets linkages: application to European data. Journal of International Money and Finance, v. 31, n. 3, p. 606-638, 2012.

AFONSO, António; GOMES, Pedro; TAAMOUTI, Abderrahim. Sovereign credit ratings, market volatility, and financial gains. Computational Statistics \& Data Analysis, v. 76, p. 20-33, 2014.

BARRON, Michael J.; CLARE, Andrew D.; THOMAS, Stephen H. The effect of bond rating changes and new ratings on UK stock returns. Journal of Business Finance \& Accounting, v. 24, n. 3, p. 497-509, 1997.

BARBOZA, Ricardo de Menezes. Taxa de juros e mecanismos de transmissão da política monetária no Brasil. Brazilian Journal of Political Economy, v. 35, n. I, p. I33-I55, 2015.

BENNINGA, S. Financial modeling. London: MIT Press Books, 2008.

BLOOMBERG. Banco de dados. Acesso entre 01 de novembro de 2015 e fevereiro de 2016.

BRANDIMARTE, Walter. Brazil to get investment grade in 2008-analysts. Reuters reuters.com. Recuperado de https://www.reuters. com/article/brazil-debt-ratings-idUSNI7357757200705I 7

BROOKS, R.; FAFF, R.; HILLER, D.; HILLER, J. Do stock markets react to the re-rating of sovereign risk? Jassa, v. 2 I , n.3, p. 2-8, 2003.

The national market impact of sovereign rating changes. Journal of banking \& finance, v. 28, n. I, p. 233-250, 2004.

CAMARGOS, Marcos Antônio de; BARBOSA, Francisco Vidal. Estudos de Evento: teoria e operacionalização. REGE Revista de Gestão, v. I0, n. 3, p. 4I-55, 2010.
CANTOR, Richard; PACKER, Frank. Differences of opinion and selection bias in the credit rating industry. Journal of Banking \& Finance, v. 2 I, n. 10, p. I395-I4I7, 1997.

CASELLI, Stefano; GANDOLFI, Gino; SOANA, Maria Gaia. The impact of sovereign rating news on European banks. European Financial Management, v. 22, n. I, p. |42-167, 2016.

CASTRO, P. R. Risco: vale a pena medi-lo? In: SR Rating: Papers SR, n. 6, Documento SR Rating, 200I.

CHRISTOPHER, Rachel; KIM, SukJoong; WU, Eliza. Do sovereign credit ratings influence regional stock and bond market interdependencies in emerging countries? Journal of International Financial Markets, Institutions and Money, v. 22, n. 4, p. 1070-1089, 2012.

ELTON, J. Edwuin; GRUBER J. Martin; BROWN, J. Stephen; GOETZMANN, N. WILLIAM. Moderna teoria de carteiras e análise de investimentos. Rio de Janeiro: Elsevier, 2012.

EDERINGTON, Louis H.; GOH, Jeremy $\mathrm{C}$. Bond rating agencies and stock analysts: who knows what when? Journal of Financial and Quantitative Analysis, v. 33, n. 4, p. 569-585, 1998.

ERB, Claude B.; HARVEY, Campbell R.; VISKANTA, Tadas E. Political risk, economic risk, and financial risk. Financial Analysts Journal, v. 52, n. 6, p. 29-46, 1996.

FERREIRA, Miguel A.; GAMA, Paulo $M$. Does sovereign debt ratings news spill over to international stock markets? Journal of Banking \& Finance, v. 31, n. I0, p. 3 |62-3 I82, 2007.

FOLLOWILL, Richard A.; MARTELL, Terrence. Bond review and rating change announcements: An exa- mination of informational value and market efficiency. Journal of Economics and Finance, v. 21 , n. 2, p. 75-82, 1997.

FREITAS, Abner de Pinho Nogueira; MINARDI, Andrea Maria Accioly Fonseca. The impact of credit rating changes in Latin American stock markets. BAR-Brazilian Administration Review, v. 10, n. 4, p. 439-46I, 2013.

GANDE, Amar; PARSLEY, David C. News spillovers in the sovereign debt market. Journal of Financial Economics, v. 75, n. 3, p. 69l-734, 2005.

GRAY, Stephen; MIRKOVIC, Alexsander; RAGUNATHAN,Vanitha.The determinants of credit ratings: Australian evidence. Australian Journal of Management, v. 3I, n. 2, p. 333-354, 2006.

GRIFFIN, Paul A.; SANVICENTE, Antonio Z. Common stock returns and rating changes: $A$ methodological comparison. The Journal of Finance, v. 37, n. I, p. I03-II9, 1982.

GOH, Jeremy C.; EDERINGTON, Louis $\mathrm{H}$. Is a bond rating downgrade bad news, good news, or no news for stockholders? The Journal of Finance, v. 48, n. 5, p. 200I-2008, I 993.

. Cross-sectional variation in the stock market reaction to bond rating changes. The Quarterly Review of Economics and Finance, v.39, n.5, p.101-122, 1999.

GUIA RÁPIDO: AGÊNCIAS DE RATING. Instituto Brasileiro de Relações com Investidores (IBRI), 2016. Disponível em: < http:// www.ibri.com.br/Upload/Arquivos/guia_rapido_rating.pdf $>$. Acesso em: 0I fev. 2016.

HILL, Paula; FAFF, Robert. The market impact of relative agency activity in the sovereign ratings market. Journal of Business 
Finance \& Accounting, v. 37, n. 9-10, p. 1309-1347, 2010.

HAN, Seung Hun et al. Market segmentation effects in corporate credit rating changes: The case of emerging markets. Journal of Financial Services Research, v. 35, n. 2, p. |4|-166, 2009.

HAND, John RM; HOLTHAUSEN, Robert W.; LEFTWICH*, RICHARD $W$. The effect of bond rating agency announcements on bond and stock prices. The journal of finance, v. 47, n. 2, p. 733-752, 1992.

HOLTHAUSEN, Robert W.; LEFTWI$\mathrm{CH}$, Richard W. The effect of bond rating changes on common stock prices. Journal of Financial Economics, v. 17, n. I, p. 57-89, 1986.

JORION, Philippe; ZHANG, Gaiyan. Information effects of bond rating changes: The role of the rating prior to the announcement. The Journal of Fixed Income, v. 16, n. 4, p. 45-59, 2007.

JORION, Philippe; LIU, Zhu; SHI, Charles. Informational effects of regulation FD: evidence from rating agencies. Journal of financial economics, v. 76, n. 2, p. 309-330, 2005.

KIM, Hyunjoon; GU, Zheng. Financial determinants of corporate bond ratings: an examination of hotel and casino firms. Journal of Hospitality \& Tourism Research, v. 28, n. I, p. 95- 108, 2004.

LANGOHR, Herwig; LANGOHR, Patricia. The rating agencies and their credit ratings: what they are, how they work, and why they are relevant. John Wiley \& Sons, 2010.

LI, Joanne; SHIN, Yoon S.; MOORE, William T. Reactions of Japanese markets to changes in credit ratings by global and local agencies. Journal of Banking \& Finance, v. 30, n. 3, p. I007-I02I, 2006.

DE LIMA, Gerlando Augusto Sampaio Franco; YAMAMOTO, Ma- rina Mitiyo; LIMA, Iran Siqueira; MALACRIDA, Mara Jane Contrera. Um estudo da eficiência informacional do mercado acionário brasileiro. RIC-Revista de Informação Contábil-ISSN: 1982-3967, v. 2, n. I, 2008.

LÓPEZ, Raquel Flórez. Análisis de los Determinantes del Riesgo de Crédito. Aplicación de Técnicas Emergentes en el Marco de los Acuerdos de Basilea II y Solvencia II. Revista Española de Financiación y Contabilidad, p. 649-653, 2007.

MACIEL, João Victor Soares; DE CAMARGOS, Marcos Antônio. Impacto da alteração do rating soberano no custo de capital de empresas brasileiras, 20052015. Revista Pretexto, v. 19, n. 3, p. 99-।I8, 2018.

MACKINLAY, A. Craig. Event studies in economics and finance. Journal of economic literature, $v$. 35, n. I, p. 13-39, 1997.

MALKIEL, Burton G.; FAMA, Eugene F. Efficient capital markets: A review of theory and empirical work. The journal of Finance, v. 25, n. 2, p. 383-4I7, 1970.

MARKOSKI, Ângela Silva; MOREIRA, Roberto Moreno. Efeitos do rating soberano brasileiro sobre o lbovespa: observações entre janeiro de 1994 e julho de 2003. 2010.

MATOUSEK, Roman; STEWART, Chris. A note on ratings of international banks. Journal of Financial Regulation and Compliance, v. 17, n. 2, p. I46-155, 2009.

MATOLCSY, Zoltan Paul; LIANTO, Thomas. The incremental information content of bond rating revisions: The Australian evidence. Journal of Banking \& Finance, v. I9, n. 5, p. 891-902, 1995. NAYAR, Nandkumar; ROZEFF, Michael S. Ratings, commercial paper, and equity returns. The Journal of finance, v. 49, n. 4, p. 143I-I449, 1994.
POON, Winnie PH; CHAN, Kam C. An empirical examination of the informational content of credit ratings in China. Journal of Business Research, v. 6I, n. 7, p. 790-797, 2008.

PURDA, Lynnette D. Stock market reaction to anticipated versus surprise rating changes. Journal of Financial Research, v. 30, n. 2, p. 30I-320, 2007.

SERRA, R. G.; WICKERT, M. Valuation: guia fundamental. São Paulo:Atlas, 2019.

DE SOUZA MÚRCIA, Flávia Cruz; MÚRCIA, Fernando Dal-Ri; BORBA, José Alonso. The Informational Content of Credit Ratings in Brazil: An Event Study. Brazilian Review of Finance, v. II, n. 4, p. 503-526, 2013. Standard \& Poor's. 201I. Guide to Credit Rating Essentials: What are Credit Ratings and How Do They Work? 20I I. Disponível em: <http://img.en25.com/Web/StandardandPoors/SP_CreditRatingsGuide. pdf $>$. Acesso em: 12 fev. 2016.

STEVENSON, Wiliam J.; DE FARIAS, Alfredo Alves. Estatística aplicada à administração. 198। .

CLASSIFICAÇÃO DE RISCO DA REPÚBLICA SOBERANA DO BRASIL. Tesouro Nacional, 2016. Disponível em: <https://www.tesouro. gov.br/web/stn/-/classificacao-de-risco-da-republica-soberana-do-brasil>.Acesso em: 08 jan. 2016.

TERRA, Paulo Renato Soares; LIMA, João Batista Nast de. Governança corporativa e a reação do mercado de capitais à divulgação das informações contábeis. Revista Contabilidade \& Finanças, v. 17, n. 42, p. 35-49, 2006.

WILLIAMS, Gwion; ALSAKKA, Rasha; AP GWILYM, Owain. The impact of sovereign rating actions on bank ratings in emerging markets. Journal of Banking \& Finance, v. 37 , n. 2, p. 563-577, 2013. 